\title{
URGE REDISEÑAR EL SERVICIO CIVIL DE CARRERA DEL CONGRESO MEXICANO
}

\author{
Cecilia MORA-DONATTO*
}

RESUMEN: Este artículo ofrece una visión panorámica de las diversas asambleas representativas latinoamericanas y de países europeos que cuentan con servicio técnico de apoyo parlamentario. Dedica un apartado a dos sistemas que sugiere como coordenadas para el caso mexicano. El primero es el Congressional Research Service con una trayectoria histórica que ha contribuido a que la información del Congreso estadounidense sea veraz, oportuna y sirva a los legisladores en el momento de tomar decisiones legislativas y de control al Ejecutivo, entre otras; el otro extremo del eje es el Cuerpo de Letrados de las Cortes españolas. Después de este análisis de derecho comparado, se analiza el caso del Congreso mexicano mostrando las fortalezas del diseño institucional de este servicio y las debilidades que se han manifestado desde el año 2000 a la fecha. Finalmente, la autora delinea de manera clara y contundente cuál es su concepción y cómo debe funcionar, desde su perspectiva, un servicio de esta naturaleza en el Congreso mexicano.

Palabras clave: Servicio Civil de Carrera, Congreso de los Estados Unidos Mexicanos, Servicios Parlamentarios, Legisladores.
ABSTRACT: This article's offer an overview regarding several both Latin-American and European representative assemblies having technical parliamentary support service. A section is dedicated to both systems, the ones suggested as landmarks for Mexican case. The first one: Congressional Research Service, showing a very important historical background which doubtlessly has contributed to American Congress' veracity and convenience and so it is useful for legislators when taking legislative and Executive's control decisions and so on. In the other hand, much more recently, we have literate corpus, whose consolidation and efficiency are shown at Spaniard Courts. After this Comparative Law's analysis, Mexican Congress' case is analyzed; it shows not only strengths but also weaknesses manifested from year 2000 to nowadays. Finally, author clearly and firmly remarks her point of view: She says, in her own, how this kind of service should work at Mexican Congress.

Descriptors: Service Career, Mexican Congress, Parliamentary Services, Legislators.

* Investigadora en el Instituto de Investigaciones Jurídicas de la UNAM.

Fecha de recepción: 13 de agosto de 2007.

Fecha de dictamen: 26 de febrero de 2008. 


\section{INTRODUCCIÓN. IMPORTANCIA DEL SERVICIO CIVIL EN LOS ÓRGANOS PARLAMENTARIOS}

La premisa básica y fundamental de la que queremos partir en este ensayo es la de establecer la diferencia que existe entre el político profesional (en este caso los legisladores) y el asesor institucional. El primero, desarrolla una actividad constitucional y legalmente relevante para el sistema representativo y democrático rigiéndose exclusivamente bajo el criterio de oportunidad política. Mientras que el asesor institucional, despliega una actividad de extraordinaria importancia al servicio de las funciones parlamentarias con arreglo a los principios de legalidad, objetividad e imparcialidad.

En el contexto político actual en el que está desarrollando su actividad el Congreso de la Unión, resulta evidente la necesidad contar con un apoyo técnico, profesional y permanente para nuestros legisladores. Hasta ahora los asesores eventuales o personales de nuestros representantes nada tienen que ver con los modernos y sofisticados staff o grupos de asesores con que cuentan la mayor parte de los parlamentos contemporáneos. Cada vez son mayores los ámbitos en los que interviene el Poder Legislativo y los problemas que tiene que enfrentar también son más complejos, específicos y técnicos, por lo que resulta francamente increíble pretender que cada uno de los legisladores, o todos en su conjunto, sean especialistas en materias técnicas como la generación de energía nuclear, el genoma humano, la petroquímica, por sólo citar algunos.

La función legislativa, ni duda cabe, requiere en nuestro país de un replanteamiento serio. No podemos seguir legislando con base en buenos propósitos. Es necesario que se legisle bien y únicamente lo estrictamente necesario. ${ }^{1}$ Para lograr lo anterior se requiere analizar con detenimiento cuáles son los problemas y cuáles las alternativas de solución; pues no todos los problemas que enfrentan los Estados contemporáneos pueden ser solucionados con la publicación de una ley, esta visión imperante durante largas décadas en nuestro país, es obvio, ha llegado a su fin y la ley ha dado sobradas muestras de sus límites. Para que el Congreso apruebe una ley que contribuya a la solución de los problemas nacionales actuales y que no quede simplemente en letra muerta, necesitamos un

1 Sobre el particular puede verse Mora-Donatto, Cecilia, Teoría de la legislación, Bogotá, Universidad Externado de Colombia, 2003. 
cuerpo técnico que mediante el estudio y el análisis nos diga con exactitud qué ley y con base en qué fundamentos teóricos y prácticos debe convertirse en derecho vigente. Así como conocer, con anterioridad a su publicación, cuáles serán, previsible y potencialmente, los resultados que se obtendrán, mediante la aplicación de la misma.

La función de control, asimismo, requiere de un extraordinario mecanismo de apoyo para que nuestros legisladores sean capaces de conocer con profundidad los ámbitos en los que el Ejecutivo asume decisiones y cuál será la mejor manera en la que el Congreso pueda controlar sus actividades. Estos dos enfoques parten de una premisa básica: a los legisladores les corresponde asumir la decisión política en cada asunto y a los órganos técnicos aportar la información, documentos, datos, estudios y análisis para que eso sea posible. Debe quedar claro que los órganos técnicos de apoyo no vienen a sustituir la voluntad del legislador. Sirven para ayudar al legislador para que sus decisiones sean, cada vez más, el producto de amplias reflexiones y de solventes estudios que permitan que los legisladores razonen y fundamenten su voto. Ni siquiera pensamos que los ayude a tomar la mejor decisión política, eso es quizá subjetivo. Los órganos técnicos de apoyo son para que el legislador fundamente en datos y análisis objetivos el sentido de su voto.

\section{VISIÓN PANORÁMICA INTERNACIONAL DE LOS SERVICIOS DE APOYO TÉCNICO}

En el apartado siguiente haremos un breve recorrido por los servicios que diversos parlamentos han dispuesto para apoyar sus trabajos; dividiremos este apartado en dos rubros, el primero lo dedicaremos a destacar algunos servicios en los congresos de América Latina y el segundo a los parlamentos de Europa occidental.

\section{América Latina}

\section{A. Argentina}

La República de Argentina tiene un Congreso Nacional, integrado por dos cámaras: la de Diputados cuenta con un total de 257 legisladores. Mientras que el Senado se compone por 72 senadores. El servicio de re- 
ferencia legislativa es el Centro de Información y Asesoramiento del Congreso Nacional. Se constituye en una dirección que depende de la biblioteca del Congreso de la Nación. Sirve de apoyo a los legisladores, asesores, comisiones y demás dependencias del Congreso y se compone de los siguientes departamentos de: asistencia técnica legislativa; organización y derecho parlamentario; ordenamiento legislativo y coordinación de estudios. Dicha dirección cuenta con una plantilla de alrededor de cien investigadores. Sus principales actividades son: 1) proporcionar asesoría sobre técnica legislativa y redacción de normas jurídicas y proyectos legislativos; 2) elaborar estudios sobre derecho, teoría y práctica parlamentaria; de la organización interna y funciones del Congreso; 3) realizar análisis, sistematización y ordenamiento permanente de la legislación nacional, así como incidencias de las reformas; 4) realizar análisis, informes y estudios interdisciplinarios sobre asuntos de interés nacional, regional e internacional.

El personal de la Dirección de Referencia Legislativa es multidisciplinario, abarca diferentes áreas del conocimiento, como ciencias políticas, historia, ciencias económicas, filosofía, periodismo, derecho y ciencias sociales, ciencias de la información y comunicación, geografía, geología, sicología, química, bibliotecología, letras, idiomas, entre otras.

\section{B. Brasil}

La República Federal de Brasil cuenta con un Congreso Nacional, integrado por dos cámaras: la de Diputados tiene 81 legisladores. Mientras que el Senado se compone por 513 miembros. Los servicios de análisis e investigación son desempeñados por el Órgano de Consultoría Legislativa del Senado Federal. La Cámara de Diputados no cuenta con este tipo de servicios.

Creado en 1955, con la denominación de Asesoría, dicha Consultoría Legislativa está compuesta por profesionales altamente calificados, organizados en más de 30 áreas temáticas. Las plazas son ocupadas a través de concurso público de pruebas y títulos. Cuenta con una plantilla de 180 investigadores y está subordinado a la mesa directora. Sus actividades centrales son: 1) asesoramiento y consultoría a la mesa, a las comisiones y a los senadores, en el ejercicio de sus funciones legislativa, parlamentaria y fiscalizadora; 2) elabora minutas, informes, pronunciamientos y proposiciones legislativas (proyectos de enmienda a la Constitución, pro- 
yectos de ley, proyectos de resolución y requerimientos) además de estudios y notas técnicas sobre cuestiones de relevancia para el Congreso.

Para la mejor atención a la diversidad de temas, la Consultoría Legislativa, se estructuró en 32 áreas; éstas, a su vez, están agrupadas en cuatro núcleos básicos: derecho, economía, asuntos sociales y pronunciamientos. Cada consultor responde por una especialidad de manera integral, pudiendo actuar subsidiariamente en dos o tres diferentes de esa principal. Los trabajos pueden ser distribuidos a uno o más consultores, dependiendo de la complejidad y urgencia de los temas. Cuando es necesario, son creados grupos de trabajo específicos, por tiempo determinado.

\section{Costa Rica}

La República de Costa Rica cuenta con una Asamblea Legislativa integrada por 225 legisladores. El Departamento de Servicios Técnicos es la unidad encargada de las tareas de investigación y análisis de la Asamblea, se integra en la División Legislativa que depende de la Dirección Ejecutiva. Sus actividades fundamentales son: 1) brindar la información técnica requerida por el plenario, el directorio, las comisiones y los diputados, en la tramitación de los proyectos de ley; 2) realiza estudios y rinde los informes técnicos relativos a los proyectos de ley que se presenten en la Asamblea Legislativa; 3) evalúa las consultas que sobre el trámite legislativo le formulen la Dirección Ejecutiva y la División Legislativa; 4) asesora a los órganos legislativos en materias de fondo y de procedimientos parlamentarios; 5) realizar estudios técnicos sobre asuntos específicos de interés, a solicitud del plenario, el directorio y las comisiones, así como las consultas que sobre el trámite legislativo formulen la Dirección Ejecutiva y la División Legislativa. Además, se encarga de: 1) gestionar ante el directorio el concurso de expertos para colaborar con el trabajo parlamentario; 2) organizar y mantener un área de archivo y antecedentes; 3) realizar investigaciones sobre asuntos de interés para el Parlamento; 4) analizar, compilar y ordenar las sentencias del sala constitucional.

\section{Chile}

La República de Chile tiene un Congreso Nacional, integrado por dos cámaras: la de Diputados cuenta con 120 legisladores; mientras que el 
Senado se compone por 49. Los servicios de investigación y análisis están a cargo de la biblioteca del Congreso Nacional. El número de investigadores y analistas que corresponden al personal de ésta es de 53, entre bibliotecarios, científicos sociales, historiadores, geógrafos, abogados, entre otros. Sus actividades esenciales son asesorar a los miembros del Congreso mediante información y estudios, para facilitar la interpretación y reinterpretación de temas actuales. Sus servicios están dirigidos a los miembros del Congreso, personal administrativo del Parlamento; organismos del Estado; investigadores, egresados universitarios y público en general.

\section{Europa Occidental}

\section{A. Alemania}

El Parlamento alemán se integra por la cámara baja (Bundestag) integrada por 603 diputados y el Senado (Bundesrat) que se integra por 69 senadores. El área de investigación de la biblioteca del Bundestag tiene once departamentos de investigación y análisis; el número de investigadores es de 100, de los cuales 14 se encuentran en la biblioteca y 86 en los departamentos de investigación. En promedio cada división cuenta con ocho investigadores.

Los investigadores producen análisis, opiniones, encuestas y estudios; propuestas de reforma y ofrecen soluciones a problemas concretos; asesoría en temas constitucionales; formulan comparativos de diferentes sistemas políticos y legales; dan asistencia en cuestiones de legislación y ocasionalmente borradores de iniciativas; hacen evaluaciones, resúmenes y revisiones, así como contribuciones a la discusión, notas, documentación, compilaciones y material para discursos. Sus servicios están destinados a los miembros del Parlamento, grupos parlamentarios, administraciones parlamentarias, los miembros alemanes del Parlamento Europeo, los miembros del Bundesrat, departamentos gubernamentales en Berlín y Bonn, misiones diplomáticas en Berlín, cabilderos certificados, periodistas alemanes y extranjeros. 


\section{B. Francia}

En el Parlamento francés, integrado por una Asamblea Nacional de 577 representantes y un Senado de 321 miembros, existe un departamento de estudios y documentación adscrito a la biblioteca del Parlamento. Está organizado en cuatro divisiones integradas cada una por cinco investigadores: 1) cultura, trabajo y salud; 2) protección social; 3) asuntos económicos, financieros y presupuesto; 4) asuntos administrativos y de justicia.

Sus actividades principales son: 1) preparar y actualizar dossieres en todos los temas de interés para los parlamentarios; 2) elaborar notas a pedido de los legisladores y da asistencia en la edición de iniciativas y en las preguntas orales y escritas; 3) examinar la viabilidad de las solicitudes dirigidas al ombudsman. El Parlamento francés cuenta adicionalmente con otros servicios autónomos como son: el área de información, el servicio de archivos y el servicio de documentación extranjera.

\section{Italia}

En el Parlamento italiano, integrado por una Cámara de Diputados de 630 miembros y el Senado de 315, la investigación es desarrollada por la oficina de estudios dependiente de biblioteca, que se divide en seis departamentos, de conformidad con las temáticas de dos o más comités: 1) instituciones: materias constitucionales, justicia y asuntos internos; 2) asuntos internacionales y defensa; 3 ) economía y producción: agricultura, industria y trabajo; 4) finanzas públicas: impuestos y presupuesto; 5) medio ambiente, transporte y trabajo público; 6) asuntos sociales y culturales.

El número de investigadores es de 45 , quienes se encargan de proporcionar dossiers comentados por cada iniciativa presentada al Parlamento; reportes de investigación para la oficina del presidente de la Cámara, grupos parlamentarios y diputados individuales. Los funcionarios del servicio de investigación asisten a las reuniones de los comités a fin de anticiparse a sus necesidades. 


\section{Inglaterra}

El Parlamento inglés por conducto de la Cámara de los Comunes cuenta con la biblioteca para los servicios de investigación: House of Commons Library (HCL). Ésta, a su vez, se integra por dos departamentos: 1. Departamento Parlamentario, que integra al servicio de información para parlamentarios y su personal y el Centro de Derecho Parlamentario y Constitucional; y 2. Departamento de Investigación. Este Departamento cuenta a su vez con siete secciones: 1) comercio y transporte; 2) asuntos internos; 3) ciencia y medio ambiente; 4) educación y servicio social; 5) estadística social y general; 6) política económica y estadística; 7) asuntos internacionales y defensa. Este Departamento se anticipa a la discusión parlamentaria, elaborando estudios sobre los temas de la agenda legislativa. Atiende solicitudes de los parlamentarios y sus asesores. Sus productos son breviarios y reportes de investigación. El número de investigadores se integra por 177 funcionarios entre personal especializado y de apoyo. De éstos, 40 son especialistas del Departamento de Investigación.

En el recorrido realizado hasta aquí a ocho asambleas representativas de nuestro continente y de Europa occidental podemos apreciar que, en la mayor parte de las mismas, este tipo de órganos técnicos de asistencia parlamentaria existen y cumplen funciones similares, la diferencia entre ellos radica, fundamentalmente, en su grado de independencia y gestión y en los criterios científicos y académicos por los que se rigen. En los parlamentos de países con una mayor consolidación democrática, este tipo de servicios de apoyo técnico cuenta con un alto grado de autonomía y generalmente son adscritos a la biblioteca (Argentina, Chile, Costa Rica, Alemania, Francia, Italia, Inglaterra) por tanto no existe una subordinación de los criterios científicos y académicos que deben regir a tales servicios a los criterios políticos o de oportunidad.

\section{El Congressional RESEARCH SERVICE Y EL CUERPO DE LETRA- DOS DE LAS CORTES ESPAÑOLAS. DOS REFERENCIAS ÚTILES PARA EL CASO MEXICANO}

Hemos decidido dedicar este apartado a dos tipos de staff técnicos parlamentarios antagónicos entre sí; opuestos no sólo por su historia y tra- 
yectoria sino porque, además, funcionan en dos regímenes políticos distintos: uno presidencial y otro parlamentario. El primero es el sistema estadounidense con un itinerario histórico muy importante y una consolidación funcional extraordinaria. El segundo, el Cuerpo de Letrados Español, un organismo relativamente nuevo (creado después de la aprobación de la Constitución democrática de 1978) que, a pesar de ello, ha logrado consolidarse y alcanzado un gran prestigio. Estos dos sistemas de apoyo técnico pueden servirnos - situados uno en un extremo y otro en contraposición-, de coordenadas para entender la situación en la que México se encuentra ubicado en esta materia.

\section{Estados Unidos de América}

El Congresional Research Service (CRS) es el organismo más antiguo dentro de los servicios de apoyo al Congreso estadounidense; ${ }^{2}$ sus orígenes se remontan a 1800, año en el que se fundó la biblioteca del Congreso; pero dos años después un incendio destruyó el Capitolio y con ello los acervos que ahí se alojaban. La nueva biblioteca del Congreso empezaría a funcionar con la colección privada de Thomas Jefferson, la que incluía alrededor de 6,700 volúmenes; las primeras solicitudes de información por parte de los legisladores fue el origen de dicho organismo, mismo que se creó mediante decreto del Congreso en 1914. Originalmente se le denomino Legislative Reference Service (Servicio de Referencia Legislativa), y su objeto principal fue dar mayor apoyo al personal de la biblioteca dedicado a proporcionar información a los legisladores. A partir de esa fecha y durante los siguientes 30 años el volumen de trabajo y el presupuesto de dicho organismo dependieron de las actividades propias del Congreso; esto es, a medida que las solicitudes de información se fueron incrementando y haciendo más especializadas, se tuvo que contratar a bibliotecarios con más conocimientos teóricos y prácticos sobre temas específicos.

Otro año importante para el Congreso estadounidense - y en particular para el Legislative Reference Service - es 1946. Recién terminada la

2 Este servicio de investigación cuenta además con las oficinas de: Contaduría General (GAO), Evaluación de Tecnologías (OTA) y Presupuesto del Congreso (CBO). La Asamblea de Representantes se constituye con 435 miembros, mientras que el Senado con 100 . 
guerra mundial y tras un periodo de crisis económica se acentuó una marcada diferencia del personal del Poder Ejecutivo frente al del Legislativo, lo que reflejó una pérdida de terreno en la balanza de equilibrio de poderes, razón por la que se promulgó la Legislative Reorganization Act en la que se decretó la permanencia del servicio de referencia legislativa como un departamento independiente de la biblioteca del Congreso, autorizándolo a contratar especialistas más preparados cuyos sueldos estarían al mismo nivel que el de los puestos similares del Poder Ejecutivo. Veinticuatro años más tarde, la Legislative Reorganization Act de 1970 reforzaría no sólo la vigilancia general y especial que el Congreso ejercía sobre el Ejecutivo sino que, de la mano de dicha reforma, el Congreso buscaría su propia independencia de información, investigación y análisis respecto del Ejecutivo. Ello motivó el cambio de nombre del Legislative Reference Service por el de Congresional Research Service (Servicio de Investigaciones del Congreso).

Ese mismo año se triplicó el número de empleados y se instituyó la independencia total de la investigación y el máximo grado posible de autonomía administrativa de la biblioteca del Congreso. Del mismo modo las mencionadas enmiendas contenían disposiciones precisas sobre la función de análisis del CRS. En ellas se establecía como principal responsabilidad, sin afinidad política ni partidaria, del Congresional Research Service, la siguiente: asesorar y asistir a cualquier comité del Senado o de la Cámara de Representantes y a cualquier órgano del Congreso, cuando así lo soliciten, en el análisis y evaluación de las propuestas legislativas dentro de la competencia del comité o de las recomendaciones presentadas ante el Congreso, por el presidente o por cualquier organismo ejecutivo, de manera que ayude al comité en: a) la determinación y viabilidad de legislar sobre las propuestas legislativas; b) llevar a cabo la estimación de los probables resultados de las iniciativas y posibles alternativas; c) evaluar métodos alternativos para obtener los mismos resultados, así como llevar a cabo otros servicios de investigación y análisis que los comités estimen necesarios para el desarrollo de sus funciones; $d$ ) auxiliar en la elaboración de una base operativa para la evaluación y determinación de las propuestas y recomendaciones legislativas.

A partir de entonces y para el cumplimiento de estas funciones, el Servicio contó con la autoridad, cuando le sea otorgada por un comité, para actuar como agente del mismo y solicitar de cualquier departamento $\mathrm{u}$ 
organismo de los Estados Unidos, la reproducción de libros, archivos, correspondencia, trabajos de investigación, proyectos o cualquier otro documento que el Servicio estime necesarios y los departamentos u organismos de los Estados Unidos acatarán la solicitud. Además, para la realización de todo lo anterior, el Servicio mantendrá comunicación continua con todos los comités. ${ }^{3}$

Desde entonces y hasta nuestros días el organismo encargado de ofrecer los servicios de asesoría y asistencia al Congreso de los Estados Unidos es el Congresional Research Service. A éste le corresponde proporcionar a los legisladores servicios como: información, consulta, análisis político, organización de seminarios para legisladores y capacitación del personal del Congreso, resúmenes sobre cuestiones del Congreso, documentos de información en cintas magnetofónicas, programas en cintas de video y una extensa variedad de apoyo legislativo. Estos servicios son considerados un complemento para el personal de cada oficina legislativa, por lo que le permite al CRS tener acceso a diversos asuntos sobre las políticas del país. La información y análisis que ofrece, tanto a la mayoría como a la minoría, en ambas cámaras, es absolutamente imparcial y objetiva, esto es, no recomienda ni formula políticas legislativas. En suma, las funciones de este servicio podemos concentrarlas de la siguiente manera:

- El CRS realiza investigación y análisis sobre todas las cuestiones actuales y emergentes de la política nacional.

- Sus servicios adoptan la forma de informes, memoranda, recopilaciones, bibliografías, sesiones informativas e incluso presentaciones en medios electrónicos y audiovisuales.

- El CRS apoya a los miembros, comités y líderes de las cámaras durante todas las etapas del proceso legislativo, desde su ayuda en la evaluación de la necesidad de nueva legislación antes de que ésta se presente, hasta su asistencia técnica para que puedan llegar a un acuerdo final sobre los proyectos de ley, previamente a que sean enviados al presidente.

3 Sección 203 (d) (1) de 2 USC 166. Citado en Robinson, William, "La integración plural del Congreso. Requisito para la actualización de sus funciones", Quórum, México, segunda época, año VII, núm. 61, julio-agosto de 1998, p. 133. 
- Otros servicios son: seminarios, cursos de capacitación, asesorías breves, consultas en personas y traducciones.

- El CRS sirve exclusivamente a los miembros del Congreso, su personal, y comités.

- La biblioteca alberga un acervo de 120 millones de unidades bibliográficas, de los cuales 105,000 volúmenes pertenecen a la biblioteca del Servicio de Investigaciones para el Congreso (CRS).

Los principios que inspiran sus labores son la estricta confidencialidad e independencia, lo anterior ha sido sumamente importante pues ha tenido injerencia en las negociaciones legislativas más significativas que ha asumido el Congreso estadounidense durante el siglo pasado. Una de las características más importantes de este servicio es que posee total autonomía no sólo para desarrollar sus investigaciones sino, y quizá más importante, para administrar su presupuesto, según se establece en su estatuto interno. El número de investigadores y analistas que forman parte del personal de biblioteca son: 440 (incluyendo a 28 administradores que también son calificados como analistas sustanciales); su presupuesto - que alcanza cifras muy considerables - se distribuye de la manera siguiente: $61 \%$ investigación y análisis de políticas; $28 \%$ información; $6 \%$ documentación y 5\% dirección ejecutiva. La asignación del presupuesto refleja, sin la menor duda, que el rubro de mayor interés e importancia para el Congreso estriba en la investigación y la evaluación de políticas públicas, dos de las funciones más significativas de los parlamentos modernos. Para el desarrollo de sus funciones las divisiones de investigación interdisciplinaria con que cuente el CRS son:

\section{A. Derecho estadounidense}

A grandes rasgos, el trabajo fundamental de esta división es atender los requerimientos que le formulen los órganos del Congreso, en cualquier fase del procedimiento legislativo, relacionados con la legislación federal, estatal y el case law. Su labor es dar respuesta a los cuestionamientos sobre constitucionalidad, legalidad, separación de poderes, relaciones entre el Ejecutivo y el Legislativo, así como sobre derecho internacional. Esta área también se dedica a la actividad contenciosa que pueda llegar a afectar las labores del Congreso y asume la representación 
legal en asuntos judiciales en los que éste sea parte. Adicionalmente, su personal se encarga de la edición de la Constitución comentada, conocida como The Constitution of the United States of America - Analysis and Interpretation.

La división de derecho estadounidense está dirigida por un director auxiliar y un diputado. Se integra por 45 miembros expertos en temas como: derecho constitucional, civil, ambiental, penal, administrativo; también en ética, prácticas y procedimientos del Congreso. Los abogados de esta división provienen de las distintas escuelas de derecho de todo el país. Algunos han llegado inmediatamente después de graduarse como abogados o después de terminar el clerkships judicial, otros llegan de las agencias federales y de la academia. Aproximadamente $70 \%$ del los abogados que han trabajado en la división ha permanecido en la misma diez años o más.

\section{B. Política social interna}

Los miembros de la división de política social interna trabajan, como no puede ser de otra forma, estrechamente con los comités del Congreso proveyendo análisis e investigación en política interna y programas sociales. Los analistas utilizan una metodología interdisciplinaria para estudiar los programas y revisarlos desde un punto de vista cuantitativo y económico. Esta división desarrolla sus labores a través de las siguientes secciones: de los niños y de las familias; seguridad interna e inmigración; educación y trabajo; pensiones públicas y privadas, compensación por desempleo y prestaciones para los trabajadores; servicios médicos; política del envejecimiento; apoyo para personas discapacitadas, de la tercera edad, pobres, veteranos y minorías.

\section{Asuntos exteriores, defensa y comercio internacional}

Los analistas de esta división siguen el desarrollo político y económico mundial, incluyendo las relaciones de Estados Unidos con otros países tanto a nivel bilateral como multilateral, inclusive en asuntos de terrorismo, refugiados, problemas de la economía global e instituciones internacionales, por ejemplo, el Fondo Monetario Internacional y la Organización Mundial de Comercio. También dirigen programas de auxilio al extranjero, estrategias y asignación de recursos; el presupuesto y funcio- 
nes del Departamento de Estado; la deuda internacional; diplomacia pública y legislación en relaciones exteriores. Asimismo, incluye políticas de seguridad nacional, estrategias militares, sistemas de armamento, compensación militar, presupuesto de la defensa y bases militares americanas. Legislación relativa a los tratados internacionales, su política y programas. Promociones de exportación, regulación de importación y tarifas.

\section{Gobierno y finanzas}

A esta área le corresponde dar seguimiento a los requerimientos relacionados con la asistencia en todos los procedimientos del Congreso, como son: presupuesto y proceso de aprobación; sus procesos legislativos; divisiones legislativas, así como sus relaciones ejecutivas-legislativas. Adicionalmente, la división responde a requerimientos de los órganos del Ejecutivo; la Presidencia y vicepresidencia; relaciones intergubernamentales; gobiernos locales y estatales; el Distrito de Columbia; territorios; departamento rural y urbano; pequeños negocios y desarrollo económico; estadística de la política federal; inspección; investigación y votaciones de la opinión pública; censos; elecciones; partidos políticos; historia de Estados Unidos y su Constitución; información política y privada; banca; seguros y seguridad; análisis de la política macroeconómica; política fiscal y monetaria; impuestos y finanzas del gobierno.

\section{E. Recursos naturales, ciencia e industria}

Esta división cubre una gran diversidad de asuntos legislativos como: recursos naturales, administración del medio ambiente; ciencia y tecnología; industria e infraestructura. Sus labores se concretan en el análisis político en relación con tierras públicas y otros asuntos de recursos naturales, medio ambiente, agricultura, comida, industria pesquera; energía y minerales. Los alcances de la ciencia incluyen análisis políticos en investigación y desarrollo de asuntos civiles y militares; información en telecomunicaciones; espacio; ciencias terrestres y en general todo lo relacionado con la ciencia y la tecnología. El soporte de asuntos de la industria incluye un análisis político en asuntos de transportación; transportación de infraestructura; la estructura y regulación del mercado industrial, así como el análisis del sector específico de la industria. 
Adicionalmente el trabajo de las divisiones de la investigación de CRS es apoyado por siete oficinas de la infraestructura: asuntos del Congreso y consejero del director; finanzas y administración; información legislativa; investigación; tecnología; desarrollo de la fuerza de trabajo y la oficina del director, que incluye la oficina de comunicaciones.

Este organismo tiene una cobertura total, con una capacidad suficiente para dar respuesta inmediata a las solicitudes que se le presenten al igual que para emprender proyectos de investigación y estudios especiales. Su capacidad de respuesta es casi inmediata, el CRS contesta más de las dos terceras partes de las solicitudes el mismo día en el que se reciben y el resto se satisface a más tardar una semana después de presentada la solicitud inicial. Lo anterior en relación con su trabajo frente al Congreso; el servicio a los particulares no cuenta con la misma celeridad pero siempre se da respuesta a dichos cuestionamientos.

Existe una sección central de recepción de solicitudes la que se encarga de darles trámite y enviarlas a la división correspondiente dándoles un seguimiento a través de su sistema de cómputo. Las solicitudes consideradas como urgentes se envían de forma electrónica a la división receptora con instrucciones específicas. Dado que a la mayoría de las solicitudes se les puede dar respuesta con el material disponible, éstas se envían directamente a la División de Referencia del Congreso, la que se integra por expertos bibliotecarios de referencia; con este procedimiento se evita la carga de trabajo en las divisiones de investigación.

La División de Referencia del Congreso utiliza los informes del CRS y los resúmenes de asuntos actuales (issue briefs), colecciones de material compilado a priori conocidas como paquetes de información (info packs), archivos, recortes e impresiones técnicas de búsqueda de bases de datos computarizados y otras fuentes de referencia, de esta forma localiza los datos apropiados y los envía a la brevedad a la oficina solicitante. Por cada una de las cuestiones que el CRS recibe, se realiza un "resumen" que consta de 10 a 15 cuartillas y que debe contener lo siguiente: a) definición de la cuestión y de su evolución; b) análisis de las causas y sus soluciones alternativas; $c$ ) descripciones de los principales proyectos de ley relacionados con la cuestión; $d$ ) una cronología de sucesos, y e) referencias a otras fuentes de información y resumen inicial de una página. ${ }^{4}$

4 Robinson, William, op. cit., nota anterior, p. 113. 
Dichos issue briefs son actualizados regularmente e integrados al desarrollo de labores legislativas en proceso. Así, el resumen de asuntos actuales se constituye como el pilar de la capacidad de respuesta rápida del CRS, siendo éstos junto con los info packs los productos que representan el mayor volumen de trabajo del organismo.

\section{España}

Las Cortes Españolas se constituyen por el Congreso de los Diputados, integrado por 350 miembros, y por el Senado español, que se compone por 259 senadores. En dichas Cortes los responsables de proporcionar los servicios de información son los letrados; asesores técnico-jurídicos de dichos órganos, que además desempeñan funciones directivas en los servicios administrativos de la Cámara. Tienen como responsabilidad primordial fungir como asesores institucionales para: detectar y definir problemas; presentar dictámenes y elaborar alternativas de solución a los asuntos que se les plantean. En suma, proporcionan herramientas fundamentales que son utilizadas por los legisladores para una correcta toma de decisiones políticas.

Los letrados son asesores institucionales, es decir, desarrollan sus trabajos al servicio de la acción parlamentaria con arreglo a los principios de legalidad y eficacia, esto es, al servicio del Pleno y de cada una de las comisiones, ponencias y demás órganos que se articulan dentro del Parlamento. ${ }^{5}$ Son personal de carrera, permanente, seleccionado previo concurso de oposición que presentan licenciados en derecho con méritos, capacidad y competencia técnica. El examen de oposición para el ingreso al Cuerpo de Letrados está perfectamente estructurado y con un grado de complejidad considerable ya que comprende 450 temas relacionados con todas las disciplinas del derecho, la historia y el pensamiento político. ${ }^{6}$

5 Gonzalo Gonzalo, Manuel, "Los letrados y los servicios de información de las Cortes Españolas", Memoria del Primer Encuentro Iberoamericano de Bibliotecas Parlamentarias, México, Cámara de Diputados, 1994.

6 Los temas de examen de oposición se encuentran divididos en los siguientes grupos: teoría general del derecho; historia jurídico-política; teoría política; derecho constitucional comparado; fuentes del derecho; organización de los poderes públicos; derecho electoral; derecho parlamentario; actuación administrativa; derecho financiero; derecho civil; derecho mercantil; derecho del trabajo; derecho penal; derecho comunitario e inter- 
En virtud de la extensión de los temas que el aspirante debe dominar, son escasos los candidatos que participan en el proceso de selección y con frecuencia las plazas de las convocatorias no son plenamente cubiertas. ${ }^{7}$ La función que realizan los letrados de las Cortes Generales es similar en ambas cámaras, por lo que detallaremos lo relativo al Congreso de los Diputados y de una manera más escueta abordaremos el caso del Senado.

Corresponde a la Secretaría General ofrecer a los órganos parlamentarios y a los diputados apoyo para el desarrollo de sus tareas. Más concretamente, presta su asesoramiento jurídico y técnico a dichos órganos, facilita distintas prestaciones y organiza los medios materiales y humanos precisos para que la Cámara pueda reunirse y ejercer sus funciones. Está dirigida por el secretario general, que es nombrado por la mesa del Congreso a propuesta del presidente entre los letrados de las Cortes Generales con más de cinco años de servicios efectivos. Sus unidades básicas son, además del propio secretario general, dos secretarías generales adjuntas: una para asuntos parlamentarios y otra para asuntos administrativos. De la primera de éstas dependen las direcciones de: Asistencia Técnico-Parlamentaria, de Comisiones, de Estudios y Documentación. De la Secretaría Adjunta para asuntos Administrativos dependen las direcciones de: Asuntos Económicos e Infraestructura, de Relaciones Parlamentarias, de Gobierno Interior y la de Intervención.

En el ámbito de la Secretaría Adjunta para los Asuntos Parlamentarios se encuentran: la Dirección de Asistencia Técnico-Parlamentaria encargada de la preparación, asistencia y ejecución de los trabajos del pleno, la mesa, la junta de portavoces, así como de la redacción del Diario de Sesiones. La Dirección de Comisiones es responsable de brindar asisten-

nacional y garantías jurisdiccionales. La descripción de los 450 temas, pueden consultarse en el Boletín Oficial del Estado, núm. 54, del 4 de marzo de 1997, pp. 7090-7102.

7 El encargado de evaluar el examen de oposición es un tribunal nombrado por las mesas directivas de ambas cámaras, por lo regular integradas por: un presidente, quien es el presidente del Congreso o del Senado según corresponda; como vocales; un diputado, un senador, el secretario general del Congreso de los Diputados, el letrado mayor del Senado y un catedrático de Universidad. Como secretario del Tribunal funge un funcionario del Cuerpo de Letrados de las Cortes Generales. Los exámenes se realizan en forma escrita, duran ocho y cuatro horas cada uno; posteriormente se efectúa un examen oral. Adicionalmente se realiza un examen sobre un caso práctico relacionado con un tema jurídico-público, preferentemente de carácter parlamentario. Por último, se les hace un examen de idiomas, para ello el opositor puede elegir entre inglés, alemán o francés. 
cia, apoyo y asesoramiento a las comisiones que integran el Parlamento. $\mathrm{Su}$ desempeño operativo está basado en los criterios de imparcialidad y uniformidad, de tal forma que las diferentes comisiones se encuentran asistidas por letrados que se incorporan a ellas por sus amplios conocimientos en la materia. Sin embargo, las comisiones pueden, si así lo consideran necesario o así se requiere, solicitar a otras direcciones apoyo documental, técnico y de asesoría. Además de la asesoría parlamentaria, los letrados deben participar en las reuniones de trabajo que convoque la comisión, elaborar el orden del día, el guión para el debate interno, levantar actas y dar seguimiento a las actividades de la comisión, igualmente elaboran notas o informes que pudieran requerirles las comisiones.

Por otra parte y mucho más importante para los efectos de este ensayo se encuentra la Dirección de Estudios y Documentación, que es el área responsable de realizar los estudios e investigaciones relacionadas con la actividad parlamentaria. Elabora la base documental del material de la biblioteca, el archivo y los trabajos realizados por las distintas áreas de investigación. Para el ejercicio de su función se divide en los departamentos de:

a. Estudios: que incluye a la unidad de estudios jurídicos y parlamentarios y un área de estudios económicos;

b. Derecho comparado;

c. Documentación: constituido por las áreas de almacenamiento y tratamiento; de tratamiento de documentación en microformas y soportes especiales; de difusión que incluye a las unidades de: documentación española y comunitaria, extranjera y económica. Alberga documentación procedente de aproximadamente unas 1,500 revistas nacionales y extranjeras, documentación de organismos internacionales, capacidad de conexión en bases de datos exteriores a la Cámara, publica mensualmente un boletín, tiene convenio de cooperación con organismos públicos y privados para el intercambio de información. Responde alrededor de 100 peticiones documentales al mes;

d. Biblioteca: que cuenta con más de 131,000 títulos y adquiere alrededor de 4,000 al año, responde más de 130 peticiones bibliográficas al mes;

e. Archivo: que comprende un gran número de documentaciones, la mayoría pertenecientes al periodo constitucional de 1977; 
f. Publicaciones: sus servicios cuenta con un personal relativamente reducido pero con una gran experiencia y capacidad. Los responsables son miembros del cuerpo de archiveros-bibliotecarios de las Cortes;

g. Publicaciones oficiales.

En los servicios de documentación se han creado bases de datos de gestión y documentales respecto de las iniciativas parlamentarias, un fichero de diputados desde 1810 a la fecha, al que se le conoce con el nombre de ARGO, mismo que está en funcionamiento desde 1986. Mediante este sistema cualquier diputado puede, en cuestión de minutos, obtener información respecto del número de ocasiones que un asunto ha sido tratado en la Cámara, las posturas tanto del gobierno como de los diferentes grupos parlamentarios y el sentido en el que fue resuelto. El sistema es considerado de los más completos dentro de la Unión Europea.

El Congreso de los Diputados, con el objetivo de consolidar y perfeccionar los servicios de investigación, ha integrado una red de consulta a bases de datos, de importancia considerable para el desarrollo de los trabajos que realizan los letrados en este ámbito, que los conecta con el $\mathrm{Bo}$ letín Oficial del Estado, el Boletín de la Unión Europea, Jurisprudencia del Tribunal Europeo de los Derechos Humanos, actividad del Parlamento Europeo, así como con una conexión temporal a bases de datos de distintos parlamentos nacionales de Europa. Por otro lado, se cuenta con una recopilación de fuentes de información editadas y actualizadas en CD-Rom, como el Hansard y el Congressional Record con los debates de la Cámara de los Comunes británica y el Congreso de los Estados Unidos. Asimismo, cuenta con una hemeroteca a fin de facilitar la consulta de los diarios y la prensa escrita para conocer diariamente los acontecimientos mundiales en todos los ámbitos.

Las funciones del Cuerpo de Letrados al interior del Parlamento español es la de facilitar y enriquecer la reflexión pública sobre la acción política del gobierno, la actividad legislativa y la verificación del control parlamentario. ${ }^{8}$ Dichas funciones podemos analizarlas y entenderlas a partir de las etapas seguidas en las cámaras: ${ }^{9}$ la primera comienza cuando se somete una iniciativa de ley para su admisión o rechazo en caso de contravenir a la Constitución o al Reglamento del Congreso de los Diputados. El letrado de la Dirección de los Servicios del Pleno realiza una

8 Gonzalo Gonzalo, Manuel, op. cit., nota 5, p. 61.

9 Ibidem, pp. 61-63. 
propuesta sometiéndola al criterio de la mesa. Cuando dicha propuesta propone la no admisión de la iniciativa debe de ir acompañada de una fundamentación jurídica. Una vez que la iniciativa en cuestión es admitida, se turna a la comisión competente en razón de la materia.

La segunda etapa consiste en la elaboración de un dossier, siempre que se trate de un proyecto importante, que elabora la Dirección de Estudios y Documentación, apoyado por sus seis departamentos y servicios. Los dossier se imprimen para circulación restringida al interior de la Cámara y su extensión oscila entre las 800 y 3,000 páginas. ${ }^{10}$ La función del letrado durante esta fase es la de coordinar y dirigir los servicios documentales.

La tercera fase implica la evaluación que realiza la mesa de la comisión competente de las enmiendas presentadas por el letrado. La cuarta fase comprende dos documentos, el conocido como: "pegote" en el que se expone de manera ordenada el texto de la iniciativa por artículos, seguida de las enmiendas de supresión, situación o admisión a trámite, con lo cual se logra facilitar el debate y la votación por la ponencia y por la comisión; y la llamada: "chuleta", que consiste en una propuesta orientadora para el presidente de la comisión. Algo importante que conviene señalar aquí es que la función del letrado no termina una vez concluida la cuarta fase, pues continúa asesorando durante el debate ante el Pleno y la tramitación ante el Senado.

En otro contexto, el Cuerpo de Letrados cumple con funciones como la de brindar asesoría sobre consultas concretas relativas a problemas o cuestiones de diversos temas. Cualquier órgano de la Cámara puede solicitarles un informe que debe ser resuelto en el plazo que la misma dinámica de la Cámara lo exija; dependiendo de la urgencia, las solicitudes pueden ser resueltas en días o inclusive en horas, y su extensión puede ir desde una sencilla nota hasta un estudio amplio en el que se contemplen precedentes, derecho comparado, normas aplicables al caso concreto así

10 Un dossier de esta naturaleza contiene los siguientes apartados: a) derecho español en la materia, incluyendo la jurisprudencia y los precedentes parlamentarios más significativos; b) derecho de las comunidades autónomas; c) derecho de la Comunidad Europea, comprende las sentencias del Tribunal de Justicia de la Comunidad Europea; d) derecho comparado, estudios de las legislaciones de países como Alemania, Austria, Bélgica, Francia, Gran Bretaña, Italia, entre otros; e) datos estadísticos en lo económico y social, en los cuales se reflejen las magnitudes y realidades en las que pudiera operar el proyecto de ley en cuestión. 
como las dudas que pudiera provocar su interpretación. Además de las funciones de asesoría antes descritas, los letrados se encargan de la ejecución de los acuerdos de la Cámara, preparan las actas correspondientes y las comunicaciones necesarias.

En el ámbito administrativo, pertenecen a la Secretaría General Adjunta en la materia las siguientes oficinas:

- Dirección de Asuntos Económicos e Infraestructura cuya función principal es la de fungir como administradora de los recursos materiales y humanos de la Cámara; así como del Centro Informático.

- Dirección de Gobierno Interior a la que se encomienda el control del personal y de los servicios sociales y médicos.

Además de las anteriores direcciones, el secretario general cuenta con la Dirección de Relaciones Parlamentarias de quien depende el Departamento de Protocolo y a la que corresponde establecer comunicación con otros parlamentos. Además de contar con el personal que constituye las áreas de intervención del Congreso de los Diputados y de las Cortes Generales y de los departamentos de Asesoría Jurídica y Prensa.

Como señalábamos anteriormente, la estructura de los cuerpos de apoyo técnico en el Senado español son muy parecidos a los del Congreso de los Diputados; en el caso de la Cámara de Representación Territorial española el letrado mayor se auxilia de un letrado mayor adjunto y supervisan las siguientes direcciones, departamentos y áreas:

- Estudios y Documentación, que se divide en:

- Departamento de Estudios

- Departamento de Estudios Comunitarios

- Área de Documentación Europea

- Departamento de Archivo

- Departamento de Documentación

- Área de Documentación Española

- Área de Documentación Bibliográfica

- Departamento de Publicaciones

- Unidad de Distribución Interna y Externa

- Departamento de Biblioteca

- Área de Ingreso y Catalogación 
- Área de Información Bibliográfica - Servicio de Documentación Autonómica

- Asistencia Técnico-Parlamentaria que se integra por:

- Área de Coordinación de Bases Documentales

- Unidad de Boletín Oficial de las Cortes Generales (Senado)

- Departamento de Registro y Ejecución Documental

- Servicio de Tratamientos y Administración de Bases de Datos - Departamento de Redacción del Diario de Sesiones

- Servicio de Redacción del Diario de Sesiones

- Comisiones, que se compone de:

- Departamento de Asistencia Administrativa a las Comisiones

- Servicio de Asistencia Administrativa a las Comisiones

- Departamento de la Comisión General de las Comunidades Autónomas

- Relaciones Interparlamentarias, que consta de:

- Departamento de Relaciones Interparlamentarias

- Área de Relaciones Interparlamentarias

- Gobierno Interior, que se integra por:

- Departamento de Personal y Gobierno Interior

- Área de Personal

- Área de Gobierno Interior

- Unidad de Servicios Generales

- Servicios Médicos

- Asuntos Económicos, que se divide en:

- Departamento Económico

- Departamento de Infraestructura e Instalaciones

- Departamento de Adquisiciones y Suministros

- Intervención

- Oficina de Contabilidad

- Informática

- Departamento de Asesoramiento Técnico Informático

Por lo expuesto hasta aquí podemos afirmar que los letrados de las Cortes desempeñan una función muy relevante. Como en el caso estadounidense ajustan su actuación a un amplio sentido de institucionalidad, que se refleja de manera palmaria en el ejercicio de sus responsabilidades 
realizadas de manera imparcial, objetiva, rápida, eficaz y permanente, pero sobre todo, técnica y profesional. Sus labores deben cumplir con los criterios de responsabilidades administrativas que existen al interior de las cámaras, ambos escenarios permiten que el funcionamiento del servicio de apoyo técnico del Parlamento español no pueda ser manipulado por un único criterio político o partido.

\section{El Servicio Civil de Carrera del Congreso DE LA UNIÓN: DEBILIDADES Y FORTALEZA}

No fue sino hasta 1999 cuando la legislación que regula la organización interna del Congreso de la Unión instituyó el Servicio Civil de Carrera para ser desarrollado por sendos estatutos emitidos por ambas cámaras. A continuación haremos un breve recorrido sobre dicho Servicio del Congreso Federal que, a pesar de haber transcurrido siete años, no alcanza a entender su importancia ni encontrar su sentido y vocación.

\section{1. Órganos técnicos legislativos y administrativos de la Cámara de Diputados}

Las normas que regulan la organización técnica y administrativa de la Cámara de Diputados se encuentran en el título segundo, capítulo séptimo de la Ley Orgánica del Congreso General de los Estados Unidos Mexicanos, en el Estatuto de la Organización Técnica y Administrativa y del Servicio de Carrera de la Cámara y en el Acuerdo de la Conferencia para la Dirección y Programación de los Trabajos Legislativos. ${ }^{11}$

Para la coordinación y ejecución de las tareas que permitan el mejor cumplimiento de las funciones constitucionales y la atención eficiente de las funciones administrativas y financieras, la Cámara cuenta con los si-

11 La Ley Orgánica del Congreso General de los Estados Unidos Mexicanos, publicada en el Diario Oficial de la Federación del 3 de septiembre de 1999, con modificaciones del 31 de diciembre de 1999, 9 de octubre de 2000, 7 de diciembre de 2001, 29 de septiembre de 2003, 29 de abril de 2004, 10 de mayo de 2004, 30 de diciembre de 2004, 8 de marzo de 2005, 3 de agosto de 2005 y 30 de diciembre de 2005; todas publicadas en el Diario Oficial de la Federación. Estatuto de la Organización Técnica y Administrativa y del Servicio de Carrera de la Cámara de Diputados, publicado en el Diario Oficial de la Federación del 22 de mayo de 2000. Acuerdo de la Conferencia para la Programación de los Trabajos Legislativos, Gaceta Parlamentaria del 20 de diciembre de 2005. 
guientes órganos: 1) Secretaría General; 2) Secretaría de Servicios Parlamentarios; 3) Secretaría de Servicios Administrativos y Financieros.

Secretaría General. Es el órgano coordinador y superior de los servicios que prestan la Secretaría de Servicios Parlamentarios y la Secretaría de Servicios Administrativos y Financieros; actúa como órgano técnico de la mesa directiva, de la Conferencia y de la Junta. El secretario general es nombrado por el Pleno con el voto de las dos terceras partes de los diputados presentes, a propuesta de la Conferencia, por el término de cada legislatura, pudiendo ser relecto. En el ámbito de la Secretaría General se ubican:

- La Dirección General de Asuntos Jurídicos;

- La Unidad de Capacitación y Formación Permanente;

- La Dirección General de Resguardo y Seguridad, y

- La Dirección de Relaciones Interinstitucionales y del Protocolo.

Secretaría de Servicios Parlamentarios. El titular de esta Secretaría es el secretario de servicios parlamentarios, suple al secretario general cuando no pueda concurrir a las reuniones de la mesa directiva. Le corresponde velar por la imparcialidad de los servicios a su cargo, realizar la compilación y registro de los acuerdos, precedentes y prácticas parlamentarias, así como de estudios sobre la organización, funcionamiento y procedimientos de la Cámara y promueve investigaciones de derecho parlamentario comparado. Esta Secretaría se integra con funcionarios de carrera y confiere unidad a las direcciones generales siguientes:

- Procesos legislativos;

- Apoyo parlamentario;

- Documentación, información y análisis;

- Crónica y Gaceta Parlamentaria.

En el ámbito de la Secretaría General, pero adscritos a la de Servicios Parlamentarios, están los centros de estudios ${ }^{12}$ de:

12 No obstante que los centros de estudios se integran por personal del Servicio Civil de Carrera, cada uno de éstos es dirigido por un comité integrado por diputados, lo que induce su actividad, como veremos más adelante. 
- Finanzas Públicas;

- Derecho e Investigaciones Parlamentarias;

- Sociales y de Opinión Publica;

- Desarrollo Rural Sustentable y la Soberanía Alimentaria; y

- Adelanto de las Mujeres y la Equidad de Género.

Adicionalmente y adscrito a la biblioteca (Centro de Documentación Información y Análisis) y dependiendo de la Secretaría de Servicios Parlamentarios, se encuentra el Sistema de Investigación y Análisis que tiene como objetivo realizar investigaciones y análisis documentales especializados, sobre temas de interés legislativo relacionados con los asuntos de la agenda parlamentaria. Su trabajo involucra la síntesis y el análisis de los datos recopilados y publicados por otros autores, presentándolos de forma sintética, imparcial y objetiva, evitando expresar juicios de valor en cuanto a las acciones que deben asumir los legisladores.

Los trabajos del SIA están dirigidos a atender las solicitudes de información especializada que requieren las comisiones, comités y diputados a los que ofrecen investigación, análisis y consulta, a través de una solicitud a la Dirección del SIA, que puede ser vía telefónica, correo electrónico, por escrito o personalmente. Los trabajos que se solicitan al SIA pueden ser sobre tópicos de interés parlamentario relativos a: 1) derecho comparado; 2) antecedentes legales; 3 ) análisis de doctrina y de datos estadísticos; 4) antecedentes económicos; 5) derecho internacional y 6) referencia especializada. Los documentos que ofrece el SIA son: 1) investigaciones a solicitud de diputados, comisiones y comités, sobre temas de interés de la agenda legislativa; 2) investigaciones de temas de la agenda legislativa, las cuales están disponibles en Internet; 3) recopilaciones temáticas de información coyuntural conforme a la agenda legislativa; 4) asesorías verbales y/o escritas de atención inmediata a los diputados sobre temas de interés para su función legislativa. Las respuestas a las consultas son atendidas de manera escrita y de modo verbal, dependiendo de la amplitud y profundidad de lo solicitado.

El SIA está conformado por una dirección y cuatro subdirecciones. La Dirección del SIA, lleva a cabo funciones de supervisión, control de gestión y difusión permanente de sus actividades. Tiene a su cargo la recepción de las solicitudes de información e investigaciones y su asignación a 
la subdirección correspondiente; autorización de las investigaciones sin solicitud (de acuerdo con la agenda legislativa o a su oportunidad coyuntural); alimentación y mantenimiento de las Bases de Datos (SIA ${ }^{13} \mathrm{y}$ Diario Oficial de la Federación y Semanario Judicial de la Federación); ${ }^{14}$ operación de las redes a las que pertenece el SIA y la administración de la Red de Investigadores Parlamentarias en Línea (REDIPAL). ${ }^{15}$

Por su parte, las cuatro subdirecciones se encargan respectivamente de: 1) Política interior: realiza reportes sobre la interpretación y el alcance de las disposiciones jurídicas vigentes, estudios de antecedentes, derecho comparado, así como los efectos que la actividad de los poderes Ejecutivo y Judicial producen en el ámbito nacional. 2) Economía: desarrolla estudios de impacto micro y macroeconómicos en relación con las iniciativas y asuntos en discusión dentro de la Cámara de Diputados. 3) Política exterior: realiza estudios sobre derecho y relaciones internacionales. 4) Referencia especializada: tiene a su cargo las solicitudes de información de respuesta inmediata.

Las investigaciones permanentes del SIA son: la obra legislativa de la Cámara de Diputados. Contiene las iniciativas y minutas de ley o decreto tratados en el pleno, señalando su proceso legislativo y un resumen de su contenido, a partir de la LVIII Legislatura. Permite el acceso a la Gaceta Parlamentaria, así como al Diario Oficial, si ya fue publicada. Iniciativas de Reforma a la Constitución Política de los Estados Unidos Mexicanos: compila las iniciativas presentadas en la Cámara de Diputados, a partir de la LVIII Legislatura ordenadas cronológicamente, por orden ascendente de artículo, señalando el grupo parlamentario que las propone, con un breve resumen de su contenido. Iniciativas de Reforma a la Ley Orgánica del Congreso General de los Estados Unidos Mexicanos: re-

13 Base de datos del SIA. Permite hacer búsquedas para la localización de las investigaciones realizadas.

14 Base de datos del Diario Oficial de la Federación y el Semanario Judicial de la Federación. Contiene el proceso legislativo, un resumen de las leyes publicadas en el $D O F$ a partir de la LVIII Legislatura, así como de las resoluciones importantes para el trabajo legislativo, publicadas en el $S J F$.

15 Es un sistema de comunicación por Internet que permite a sus miembros intercambiar información en materia parlamentaria. Pretende fomentar la colaboración y experiencia profesional de los investigadores, a través del intercambio del conocimiento y experiencias en este campo. En ella participan todos los congresos locales de México y se ha ampliado a Centro, Sudamérica y El Caribe. 
úne las iniciativas presentadas ante la Cámara de Diputados a partir de la LVIII Legislatura que proponen modificar la Ley Orgánica del Congreso General. Se ordenan en forma cronológica; por artículo modificado y por grupo parlamentario que las presente; además se proporciona un resumen del objetivo planteado en cada una de ellas.

Secretaría de Servicios Administrativos y Financieros. El titular de esta Secretaría es el secretario de servicios administrativos y financieros, suple al secretario general cuando no pueda concurrir a la reunión de la Junta de Coordinación Política. Le corresponde velar por el eficiente funcionamiento de los servicios a su cargo, así como realizar estudios sobre la organización, el funcionamiento y los procedimientos de carácter administrativo y financiero de la Cámara. Dicha Secretaría se integra con funcionarios de carrera y confiere unidad a las direcciones generales siguientes: 1) finanzas; 2) programación, presupuesto y contabilidad; 3) recursos humanos; 4) recursos materiales y servicios; 5) tecnologías de información; 6) servicios a diputados.

Contraloría Interna. De acuerdo con la Ley Orgánica, la Contraloría, es el órgano encargado de recibir quejas, realizar investigaciones, llevar a cabo auditorías y aplicar los procedimientos y sanciones inherentes a las responsabilidades administrativas de los servidores públicos que prestan sus servicios a la Cámara. Se ubica en el ámbito de la Conferencia para la Dirección y Programación de los Trabajos Legislativos. Su titular es nombrado a propuesta de la Conferencia, por las dos terceras partes de los individuos presentes en el pleno.

Coordinación de Comunicación Social. Dicha Coordinación tiene a su cargo la difusión de las actividades de la Cámara, sirve de enlace con los medios de comunicación y es responsable del programa de publicaciones. Depende de la Presidencia de la mesa directiva y la designación de su titular se rige por lo dispuesto en la Ley Orgánica y el Estatuto.

Auditoría Superior de la Federación. Para la revisión de la cuenta pública, la Cámara de Diputados se apoya en la Auditoría Superior de la Federación, la que examinará si existe discrepancia entre los ingresos y los egresos de la cuenta pública o no existe exactitud o justificación en los ingresos obtenidos o en los gastos realizados, a efecto de determinar las responsabilidades de acuerdo con la ley. 


\section{Organización técnica y administrativa del Senado de la República}

Como hemos analizado, en el caso de la Cámara de Diputados, el único funcionario que no forma parte del servicio civil de carrera, porque su nombramiento corresponde al pleno, es el secretario general. En el caso del Senado, el servicio de carrera se estructura a partir de los cargos inferiores a las secretarías generales de Servicios Parlamentarios y Administrativos, de esta última depende la Tesorería de la Cámara, y las unidades administrativas que acuerde la mesa directiva. Los titulares de estas dos secretarías, así como de la Tesorería de la Cámara, serán propuestos por la mesa directiva al pleno, y serán electos por mayoría de los senadores presentes. Durarán en sus cargos por toda la legislatura, pudiendo ser relectos. Podrán ser removidos a propuesta de la mesa directiva, por causa grave, calificada por la mayoría absoluta de los senadores presentes en el pleno.

Secretaría General de Servicios Parlamentarios del Senado. Corresponderá a la Secretaría General de Servicios Parlamentarios asistir a la mesa directiva durante el desarrollo de las sesiones del pleno; recibir los documentos oficiales y de los particulares dirigidos a la Cámara, remitirlos a la mesa directiva y llevar un control del registro de los mismos; asistir a los secretarios de la Cámara en la recepción de las votaciones del pleno; auxiliar al presidente de la Junta de Coordinación Política en la elaboración del programa legislativo a desarrollar durante cada periodo de sesiones; abrir, integrar y actualizar los expedientes de los asuntos recibidos por la Cámara y supervisar el correcto manejo del libro de leyes y decretos; llevar un registro de las resoluciones, acuerdos y dictámenes emitidos por la mesa directiva y las comisiones de la Cámara, así como garantizar su publicación en el Diario de los Debates o en los medios autorizados; desahogar las consultas de carácter técnico-jurídico que le formulen las comisiones, respecto a las iniciativas de ley o decreto que estén en proceso de dictamen, con el apoyo de la unidad especializada correspondiente.

Secretaría General de Servicios Administrativos. Por su parte, la Secretaría General de Servicios Administrativos será la encargada de encabezar y dirigir los servicios administrativos, a fin de que éstos se desempeñen con eficacia; conducir las relaciones de trabajo establecidas con el personal de base de la Cámara, y administrar los recursos humanos y ma- 
teriales, así como los servicios generales, de informática, jurídicos y de seguridad de la Cámara.

Tesorería. La Tesorería, que como hemos señalado, depende de la Secretaría General de Servicios Administrativos y Financieros de la Cámara, tendrá las siguientes atribuciones: recibir de la Tesorería de la Federación los fondos correspondientes al presupuesto de egresos autorizado para cada ejercicio fiscal, conforme al calendario de ministraciones aprobado; aplicar los acuerdos de la mesa directiva de la Cámara y del pleno, relativos a la aplicación de las partidas del presupuesto de egresos de la Cámara; hacer los pagos de dietas y sueldos de los senadores y servidores públicos de la Cámara y los demás autorizados en el presupuesto; opinar sobre los asuntos financieros de la Cámara; presentar mensualmente a la Comisión de Administración un informe de la aplicación de los recursos financieros de la Cámara; descontar de las cantidades que deba entregar como dietas a los senadores, la suma que corresponda a los días que dejaren de asistir, conforme a la orden escrita del presidente de la Cámara.

Contraloría Interna. Además de la Tesorería, la Cámara de Senadores contará con una Contraloría Interna cuyo titular será designado por mayoría de los senadores presentes en el pleno a propuesta de la Junta de Coordinación Política. El contralor podrá ser removido de su cargo por causa grave, calificada por el voto de la mayoría de los senadores presentes en el pleno. Además, tendrá a su cargo la auditoría interna del ejercicio del presupuesto de egresos de la Cámara, incluyendo los recursos asignados a los grupos parlamentarios, los que deberán presentar a la misma un informe semestral con la debida justificación del uso y destino de los recursos que la Cámara les otorgue. La Contraloría, además, auditará a los grupos parlamentarios respecto del ejercicio de los recursos que les sean asignados por la Cámara y deberá presentar al pleno, por conducto de la mesa directiva, un informe semestral sobre el ejercicio del presupuesto de egresos de la Cámara, el cual, una vez aprobado, será remitido por el presidente de la Cámara a la Entidad de Fiscalización Superior de la Federación para los efectos legales conducentes.

El Servicio Civil de Carrera del Senado. Más allá de los anteriores órganos técnicos cuya designación corresponde al pleno de la Cámara, el Senado cuenta para la profesionalización y eficiencia de lo servicios parlamentarios y administrativos con un Servicio Civil de Carrera, mismo 
que se articula a través de un centro de capacitación y formación permanente de los servidores públicos del Senado, que depende de la mesa directiva, la que designa al titular del mismo. Las facultades de dicho Centro se encuentran reguladas en el Estatuto del Servicio Civil de Carrera de la Cámara de Senadores ${ }^{16}$ (ESCCS), entre otras facultades será el encargado de:

Planear, organizar, coordinar, desarrollar, controlar, evaluar y ejecutar los procesos operativos y académicos del servicio civil; emitir opinión respecto a reformas o adiciones al ESCCS; elaborar y proponer a la mesa directiva, por conducto de su presidente, los lineamientos relativos al desarrollo de los procesos de: ingreso; ocupación de vacantes; titularidad; formación, profesionalización y especialización; evaluación; promoción y ascensos; remuneraciones y estímulos; derechos y obligaciones del personal de carrera; separación, sanciones y medidas disciplinarias; recursos e inconformidades en los términos y conforme al procedimiento del ESCCS; recibir los recursos e inconformidades sobre las evaluaciones de los servidores públicos de carrera y emitir la resolución correspondiente, previo conocimiento de la mesa directiva; solicitar a la Secretaría Administrativa la tramitación de los nombramientos del personal del servicio civil; elaborar, en coordinación con la Secretaría Administrativa, el catálogo de puestos y tabulador salarial y proponerlo a la mesa directiva; elaborar, en coordinación con la Secretaría Administrativa y con la Secretaría Parlamentaria, los planes de carrera y los programas de capacitación y formación permanente del servicio civil, y proponerlos a la mesa directiva.

Asimismo, le corresponderá elaborar, proponer a la mesa directiva y ejecutar, en su caso, los proyectos de convocatoria para concursos de ingreso, ocupación de vacantes y ascenso; elaborar diagnósticos de necesidades en materia de capacitación, formación y desarrollo de los servidores públicos de carrera; impartir cursos de formación y capacitación permanente para la profesionalización y la especialización de dichos servidores; integrar el informe anual de actividades, así como los que le sean solicitados por la mesa directiva; proponer a la comisión de administración el anteproyecto de presupuesto anual, en coordinación con la Secretaría Administrativa; proponer a la mesa directiva la estructura ocu-

16 Más tardío en su aprobación que el de la Cámara de Diputados, éste se publicó en el Diario Oficial de la Federación del 22 de noviembre de 2002. 
pacional del Centro; proponer a la mesa directiva los lineamientos relativos a la administración y desarrollo del mismo; proponer a la mesa directiva el establecimiento de convenios con instituciones educativas nacionales y extranjeras que coadyuven al mejor desarrollo del servicio civil; proponer a la mesa directiva los resultados de los concursos de ingreso, ocupación de vacantes y ascenso del servicio; proponer a la mesa directiva el dictamen relativo a los reconocimientos y estímulos a que se hagan acreedores los miembros del mismo; presentar a la mesa directiva el dictamen relativo a las licencias del personal de carrera de la Cámara. Como es fácil inferir, el Centro de Capacitación, en el caso de la cámara alta, es en definitiva el que opera todo lo relativo al servicio civil de carrera.

Adicionalmente el Senado de la República cuenta con el Instituto de Investigaciones Legislativas del Senado de la República (IILSEN), que es un órgano especializado, presidido por un Senador y dependiente de la mesa directiva, encargado de desarrollar actividades de investigación, estudios y análisis relacionados con las competencias del Senado, así como el establecimiento de vínculos institucionales con organismos públicos y privados, nacionales y extranjeros con el objeto de apoyar el trabajo legislativo del Senado. Sus tareas fundamentales son: a) elaborar investigaciones, estudios y análisis relacionados con las facultades y competencias de la Cámara de Senadores; $b$ ) establecer los vínculos institucionales para acceder a fuentes especializadas de información; c) proporcionar de manera oportuna información de apoyo a la labor legislativa del Senado.

Como resulta evidente, después de esta amplia confrontación entre diversos sistemas de apoyo técnico parlamentario el caso del Congreso mexicano se vio notablemente influido por el sistema español; tal situación es mucho más notoria tratándose de la Cámara de Diputados que del Senado, pero en ambos casos, la réplica no ha dado los mismo resultados que en el sistema hispano, a pesar de que el mexicano está por cumplir ocho años de existencia. A nuestro juicio, los primeros dos obstáculos con los que se encuentra un sistema de esta naturaleza, en nuestro país, es el desinterés de los legisladores y los intereses políticos de los mismos; motivemos esta afirmación: concluida la LVII Legislatura, que aprobó la Ley Orgánica que reguló, por primera vez, el servicio civil de carrera, correspondía a la siguiente legislatura la operación de dicho servicio mediante los estatutos de ambas cámaras, que en el caso de la de 
Diputados tardaron en aprobar ocho meses y que en el caso del Senado tardó más de dos años, ¿Qué mayor muestra de desinterés necesitamos? Estatutos que, por otro lado, no se han aplicado en su totalidad en ambas cámaras.

Producto de la pluralidad en la LVIII Legislatura ningún partido obtuvo la mayoría absoluta de los escaños, lo que generó que el número de comisiones se incrementara mediante un acuerdo parlamentario, ${ }^{17}$ violatorio de la Ley Orgánica, para poder "repartir" las presidencias de éstas entre los grupos parlamentarios ahí representados; lo anterior llevó al servicio civil de carrera al olvido, porque los lugares disponibles para el personal de carrera quedaron en manos de los "asesores" de los legisladores que fueron designados libremente por el presidente de la comisión o los miembros de la misma.

Pero el caso más lamentable es el de los centros de investigación. Veamos por qué. La Ley Orgánica de 1999 crea tres centros de investigación, a saber: finanzas públicas; derecho e investigaciones parlamentarias; sociales y de opinión publica, en el ámbito de la Secretaría General, adscritos a la de Servicios Parlamentarios, para cuyo funcionamiento y de acuerdo con el Estatuto, era necesaria la integración del Consejo Directivo del Servicio de Carrera de la Cámara de Diputados, ${ }^{18}$ pero como la constitución de dicho Consejo nunca se llevó a cabo, entonces la magnífica solución que encontraron nuestros legisladores fue la de crear por cada Centro un Comité que, por decir los menos, los han encorsetado; dicho de otra forma, han asfixiado los trabajos de los centros. Los acuerdos parlamentarios ${ }^{19}$ que les han dado vida a dichos comités los conciben como los órganos de "gobierno" de los centros y tienen como atribuciones:

1. Fijar las políticas y criterios para la elaboración del programa anual de trabajo que le someta para su ratificación el secretario general de la Cámara, atendiendo a los lineamientos del artículo 46 del Estatuto

17 Nos referimos al Acuerdo Parlamentario del 29 de septiembre de 2000.

18 Integrado por: a) el secretario general de la Cámara, como presidente; b) los secretarios de servicios parlamentarios y de servicios administrativos y financieros, como vicepresidentes; c) tres vocales; y d) el coordinador de la Unidad de Capacitación y Formación Permanente, como secretario técnico.

19 Acuerdo Parlamentario del 8 de noviembre de 2000. 
de la Organización Técnica y Administrativa y del Servicio de Carrera de la Cámara de Diputados.

2. Opinar sobre el nombramiento del director general y de los demás servidores del Centro, a consulta que le haga el secretario general de la Cámara.

3. Aprobar el reglamento interno que rija el trabajo técnico y científico encargado al Centro.

4. Adoptar las medidas y decisiones relativas a la vinculación del Centro con otras instituciones similares de órganos legislativos nacionales y extranjeros.

5. Fijar los criterios a los que deberá sujetarse el Consejo Directivo del Servicio de Carrera para ejecutar las atribuciones que le confieren el artículo 144 y demás del Estatuto de la Organización Técnica y Administrativa y del Servicio de Carrera de la Cámara de Diputados.

6. Participar, a través de su representación, en las sesiones de la Conferencia para la Dirección y Programación de los Trabajos Legislativos, cuando se traten asuntos relacionados con el Centro.

7. Determinar las reglas técnicas para la articulación funcional del Centro con los servicios de bibliotecas, comisiones y comités y del archivo de la Cámara.

8. Vigilar el debido cumplimiento de las responsabilidades, funciones y tareas que asignan al Centro los artículos 35-37 y 42 del Estatuto de la Organización Técnica y Administrativa y del Servicio de Carrera de la Cámara de Diputados.

9. Gestionar ante la Junta de Coordinación Política la asignación del presupuesto del Centro para el cumplimiento de sus funciones y atribuciones.

En el caso del Centro de Derecho e Investigaciones Parlamentarias tiene atribuciones, además, para:

1. En el ámbito de su competencia, mantener relaciones con la Unión Interparlamentaria y con los parlamentos y organismos interparlamentarios regionales; $y$

2. Aprobar el programa editorial y de divulgación, así como promover las publicaciones de elevada calidad en materia jurídica y parlamentaria, que incluyan revistas, colecciones, manuales, enciclopedias, diccionarios, prontuarios y similares. 
Tratándose del Centro de Investigaciones Sociales y de Opinión Pública, su Comité promueve que el Centro programe, opere y supervise los mecanismos para la medición de la opinión pública que determine la Cámara para el cumplimiento de sus funciones y la proyección de su imagen, así como ser el vínculo con las instituciones que tengan a su cargo la aplicación de instrumentos de democracia participativa.

La anterior larga lista de atribuciones con las que cuentan los comités de los centros de investigación hacen que éstos no operen bajo criterios de calidad, excelencia y libertad académica; por el contrario, y en virtud de la omnipresencia del Comité y la repartición partidaria de los centros, se han convertido, a lo largo de más de un quinquenio, los primeros, en costosos cotos de poder partidario (a cada grupo parlamentario le corresponde un centro de investigación). Lo anterior sin considerar una evidente falta de visión para entender no sólo cómo deben funcionar estos centros, la coordinación entre los mismos y cuáles son los objetivos que deben cumplir en las amplias e importantes labores que desempeña el Congreso federal; basta con revisar, medianamente, los sitios web de los centros para darnos cuenta de que existe una falta de coordinación o rectoría si se prefiere, para que los esfuerzos de los investigadores se consoliden en proyectos que reporten beneficios colectivos y refuercen las funciones de la Cámara. Es fuerte y delicado decirlo pero, también es necesario, los centros de investigación de la Cámara de Diputados no están cumpliendo con los fines y objetivos para los que fueron creados.

Aunado a lo anterior, no hay que dejar de lado el camino falso de la "centromanía" que ha seguido la Cámara de Diputados, a partir de 2004, y que por la vía de las reformas al artículo 49 inciso 3 de la Ley Orgáni$\mathrm{ca}^{20}$ han venido a incrementar las lista de los centros disfuncionales de la Cámara de Diputados, dos más: el de Desarrollo Rural Sustentable y la Soberanía Alimentaria; y el de Adelanto de las Mujeres y la Equidad de Género. Convendría preguntarnos ¿cuánto le cuesta al erario público la investigación que se hace en los centros de la Cámara? ¿cuántas instituciones de prestigio y de probada solvencia académica se verían beneficiadas con los ingresos que para investigación se destinan a la Cámara de Diputados?

20 Reformas publicadas en el Diario Oficial de la Federación del 10 de mayo de 2004 y 3 de agosto de 2005. 
Un aspecto más que ha ido en contra de la instauración del servicio civil de carrera en la Cámara de Diputados es la llamada: "Reingeniería de la estructura organizacional de la Secretaría General, Secretaría de Servicios Parlamentarios y Secretaría Administrativa y Financiera" que, nuevamente, por la vía de un acuerdo parlamentario ${ }^{21}$ que aprobó la LIX Legislatura, en franca violación a la Ley Orgánica, rediseñó esas secretarías que por largo tiempo han estado, ambas, en diversas etapas, en manos de encargados de despacho. Así pues, la Cámara desde 2005 ha venido funcionando con un rediseño aprobado por la Conferencia para la Dirección y Programación de los Trabajos Legislativos que no se corresponde ni con la Ley Orgánica, ni con el Estatuto de la Organización Técnica y Administrativa y del Servicio de Carrera de la Cámara de Diputados. Frente a este "caos normativo", que ha provocado la sustitución de directores y la deserción de investigadores parlamentarios, no hay servicio de apoyo técnico que pueda instaurarse, funcionar, crecer, fortalecerse y ofrecer resultados.

Hasta aquí han quedado expuestas las debilidades del servicio civil de carrera principalmente de la Cámara de Diputados porque el servicio del Senado ha sido mucho más tardío en su instauración; pero las mismas críticas fundadas que hemos realizado a los centros de investigación de la cámara baja cabrían, mutatis mutandi, para el caso del Instituto de Investigaciones Legislativas del Senado de la República (IILSEN) que no sólo depende de la mesa directiva del Senado, sino que es presidido por un senador. Situación que no hace más que confirmar, como cierta, la premisa con la que empezábamos este ensayo en el sentido de que no se entiende, en nuestra incipiente vida parlamentaria, la diferencia entre el ámbito de la decisión política y la esfera estrictamente técnica y científica que contribuye con la anterior, pero se diferencia de la misma.

No obstante, el servicio civil de carrera del Congreso federal tiene una enorme fortaleza: es aún nuevo, no ha terminado de cuajar y por ello permite su reorientación y rediseño. Mismo que deberá darse con una perspectiva de etapas a satisfacer y que en un corto tiempo permita su consolidación.

21 Acuerdo parlamentario del 4 de noviembre de 2005, publicado en la Gaceta Parlamentaria del 20 de diciembre de ese mismo año. 


\section{CONCLUSIONES PROSPECTIVAS}

1. En este artículo hicimos un recorrido por diez sistemas de asesoramiento técnico de distintos parlamentos, llegando a la convicción de que los servicios que cuentan con un considerable grado de autonomía son los que reportan mejores beneficios a los legisladores cuando éstos tienen que asumir decisiones trascendentales.

2. Para que dicha autonomía sea una realidad es conveniente que tales servicios dependan de las bibliotecas de los congresos o parlamentos. En éstas se encuentran las condiciones necesarias para que dicho servicio pueda cumplir con los principios de: imparcialidad, objetividad, rapidez, eficacia, libertad académica y permanencia. Desde luego que no son los únicos lugares, pero la historia demuestra que en las bibliotecas es en donde han nacido y se han consolidado lo mejores servicios de apoyo técnico.

3. Todos los servicios técnicos de apoyo parlamentario deben tener un órgano rector experto no partidista que conduzca, impulse y evalúe los trabajos del servicio, de tal manera que dicho órgano rector sea el garante de los principios antes enunciados.

4. Todos los miembros de los órganos técnicos y administrativos deben formar parte del servicio de apoyo técnico y los nombramientos de los cargos más altos del escalafón deberán cubrirse con los servidores con mayor conocimiento y antigüedad. Un buen ejemplo de ello es el Cuerpo de Letrados del Parlamento Español.

5. Las funciones que cumple el servicio de carrera deben estar dirigidas o encaminadas al fortalecimiento de las funciones que desempeña el Parlamento, esto es, servicio de apoyo técnico y facultades parlamentarias deben transitar por el mismo camino, pero cada uno en su propia vía. Unos - los legisladores - asumen las decisiones políticas, otros - los servicios de apoyo técnico — contribuyen a que dichas decisiones se transformen en normas eficaces.

6. En la creación y consolidación de un servicio de apoyo técnico para los congresos deben dejarse de lado los criterios partidistas o políticos, e imperar en su lógica de trabajo los criterios científicos y académicos. Por tanto, deben contribuir al acercamiento de la técnica y la ciencia a las grandes definiciones legislativas.

7. Con base en el análisis de los anteriores servicios de apoyo podemos afirmar que éstos se desarrollan en diversas fases o etapas, es decir, 
una parte de los cuerpos de apoyo técnico contribuyen a la solución de las problemáticas diarias, constantes, comunes de todos los días. Otras áreas o secciones se adelantan a los problemas que puedan presentarse en los órganos internos (de gobierno: mesa directiva, Junta de Coordinación, etcétera, o de trabajo: comisiones); y otras áreas desarrollan sus labores e investigaciones para solucionar problemas de larga tramitación en los que el Congreso está interesado en participar.

8. Los apoyos técnicos tienen que ser, por tanto, inmediatos, mediatos y a largo plazo. Los primeros reforzarán los trabajos diarios de las comisiones (secretarios técnicos, asesores, etcétera); los mediatos contribuyen con las facultades más relevantes del Congreso (legislativa, de control evaluatorio, de control parlamentario, de investigación, etcétera) los de largo plazo realizan, fundamentalmente, investigación que presente alternativas a los problemas crónicos o de mayor envergadura que debe enfrentar el Congreso.

9. Premisa fundamental de todo servicio de apoyo técnico es la estabilidad legal y funcional. Ningún servicio de esta naturaleza puede consolidarse si la normatividad que lo rige es excesivamente cambiante. La estabilidad en el empleo y la certeza jurídica de que únicamente los méritos académicos y laborales, así como la capacitación, serán los únicos parámetros valorativos para buscar los ascensos son indispensables. Sólo tales parámetros pueden desterrar de una vez y para siempre el amiguismo y el compadrazgo.

10. Un servicio de apoyo técnico equilibrado debe permitir a los legisladores la contratación libre de sus asesores o colaboradores más cercanos, pero la ley debe prever las modalidades bajo las cuales dichas contrataciones deberán hacerse, así como el número determinado de las mismas.

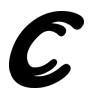

